\title{
Cardiomyocyte expression of PPAR $\gamma$ leads to cardiac dysfunction in mice
}

\author{
Ni-Huiping Son, ${ }^{1}$ Tae-Sik Park, ${ }^{1}$ Haruyo Yamashita, ${ }^{1}$ Masayoshi Yokoyama, ${ }^{1}$ Lesley A. Huggins, ${ }^{1}$ \\ Kazue Okajima, ${ }^{2}$ Shunichi Homma, ${ }^{2}$ Matthias J. Szabolcs, ${ }^{3}$ Li-Shin Huang, ${ }^{1}$ and Ira J. Goldberg ${ }^{1,2}$
}

1Division of Preventive Medicine and Nutrition and ${ }^{2}$ Division of Cardiology, Department of Medicine, and ${ }^{3}$ Department of Pathology, Columbia University College of Physicians and Surgeons, New York, New York, USA.

\begin{abstract}
Three forms of PPARs are expressed in the heart. In animal models, PPAR $\gamma$ agonist treatment improves lipotoxic cardiomyopathy; however, PPAR $\gamma$ agonist treatment of humans is associated with peripheral edema and increased heart failure. To directly assess effects of increased PPAR $\gamma$ on heart function, we created transgenic mice expressing PPAR $\gamma 1$ in the heart via the cardiac $\alpha$-myosin heavy chain ( $\alpha$-MHC) promoter. PPAR $\gamma 1$-transgenic mice had increased cardiac expression of fatty acid oxidation genes and increased lipoprotein triglyceride (TG) uptake. Unlike in cardiac PPAR $\alpha$-transgenic mice, heart glucose transporter 4 (GLUT4) mRNA expression and glucose uptake were not decreased. PPAR $\gamma 1$-transgenic mice developed a dilated cardiomyopathy associated with increased lipid and glycogen stores, distorted architecture of the mitochondrial inner matrix, and disrupted cristae. Thus, while PPAR $\gamma$ agonists appear to have multiple beneficial effects, their direct actions on the myocardium have the potential to lead to deterioration in heart function.
\end{abstract}

\section{Introduction}

PPARs play a central role in cellular and tissue metabolism (1) and affect inflammatory processes (2). Several of these receptors have been studied in the heart, one of the most energy-demanding organs in the body. Heart energy is primarily derived from oxidation of fatty acids (FAs), and this correlates with the relatively high levels of PPAR $\alpha$ expression in the heart (3). In contrast, PPAR $\gamma$ is expressed at relatively low levels in the heart. Nonetheless, recent data have shown that tissue-specific loss of PPAR $\gamma$ alters heart function (4). Moreover, rosiglitazone still caused cardiac hypertrophy in these mice, indicating non-PPAR $\gamma$ effects of the drug and highlighting the difficulty of relying on pharmacologic agents to understand the biologic actions of specific transcription factors.

In other tissues, PPAR $\gamma$ regulates tissue triglyceride (TG) accumulation. Hepatocyte overexpression of PPAR $\gamma$ leads to steatosis (5); loss of adipose tissue PPAR $\gamma$ leads to defective production of mature adipocytes (6). Whether PPAR $\gamma$ in the heart can function in a similar manner is not known.

Increased accumulation of lipids leads to organ dysfunction, a process termed lipotoxicity. In the heart, defects in lipid metabolism, diabetes, and severe obesity can cause dilated cardiomyopathy (7). This disorder has been modeled in animals. Cardiac overexpression of PPAR $\alpha$ increases FA oxidation, but it also leads to heart lipid accumulation (8). Severe obesity associated with defective leptin actions (9) and genetic alterations that increase heart lipid due to greater uptake (10) or increased FA trapping (11) also cause lipotoxic cardiomyopathies.

In some rodent models of lipotoxic dilated cardiomyopathy, PPAR $\gamma$ agonist treatment improves heart function $(12,13)$. It has

Nonstandard abbreviations used: ADRP, adipose differentiation-related protein; AOX, acyl-CoA oxidase; CD36, FA translocase; CHOP, CCAAT/enhancer-binding protein (C/EBP) homologous protein; CPT1, carnitine palmitoyl transferase-1; FA, fatty acid; FAS, FA synthase; GLUT4, glucose transporter 4; MEF, myocyte enhancer factor; $\alpha$-MHC, $\alpha$-myosin heavy chain; PGC1, PPAR $\gamma$ coactivator 1 ; qRT-PCR, real-time quantitative RT-PCR; TG, triglyceride.

Conflict of interest: The authors have declared that no conflict of interest exists. Citation for this article: J. Clin. Invest. 117:2791-2801 (2007). doi:10.1172/JCI30335. been postulated that PPAR $\gamma$ agonists have salutary effects due to direct actions on the heart (14-16); this is surprising, since PPAR $\gamma$ causes lipid accumulation in other tissues. PPAR $\gamma$ agonists have a variety of systemic effects, and, most remarkably, they channel a greater proportion of plasma TG and FA to adipose tissue (17). Such an action alone could reduce lipid uptake by the heart and improve lipotoxicity.

To directly assess effects of increased PPAR $\gamma$ on heart function, lipid metabolism, and gene expression, we created transgenic mice expressing PPAR $\gamma 1$ via the cardiac $\alpha$-myosin heavy chain ( $\alpha$-MHC) promoter. These mice have increased cardiac uptake of FA and no reduction in glucose uptake and develop dilated cardiomyopathy. Although PPAR $\gamma$ agonists did not increase cardiac gene expression in wild-type mice, these drugs increased mRNA levels of FA oxidation and uptake genes and exacerbated heart dysfunction in PPAR $\gamma$-transgenic animals.

\section{Results}

Creation of cardiac-specific PPAR $\gamma 1-$ transgenic mice. Mice overexpressing PPAR $\gamma$ in cardiomyocytes via the $\alpha$-MHC promoter were designated MHC-PPAR $\gamma 1$ mice (Figure 1A). PCR screening of the offspring identified 3 founders harboring the MHC-PPAR $\gamma 1$ transgene. Offspring from 2 of these founders, designated MHCPPAR $\gamma 1 \mathrm{~L}$ (low-expressing) and MHC-PPAR $\gamma 1 \mathrm{H}$ (high-expressing), were used in this report. Male mice were used in the experiments unless indicated otherwise. The PPAR $\gamma 1$ transgene was expressed specifically in the heart; no expression was detected in the liver, skeletal muscle, or fat (Figure 1B). In control mouse hearts, PPAR $\gamma 1$ mRNA levels were low; the ratio of PPAR $\gamma$ to $18 \mathrm{~S}$ rRNA was much lower in control heart than adipose tissue. In contrast, MHC-PPAR $\gamma 1 \mathrm{~L}$ mice had PPAR $\gamma$ to $18 \mathrm{~S}$ rRNA levels approximately twice those found in adipose tissue (Figure 1C). MHCPPAR $\gamma 1 \mathrm{H}$ hearts had PPAR $\gamma$ mRNA levels approximately 10 -fold higher than those in MHC-PPAR $\gamma 1 \mathrm{~L}$ hearts. PPAR $\gamma$ protein levels were 1.9-fold (MHC-PPAR $\gamma 1 \mathrm{~L}$ ) and 7.2-fold (MHC-PPAR $\gamma 1 \mathrm{H})$ higher in the cardiac ventricles of transgenic mice than littermate controls (Figure 1, D and E). 
A

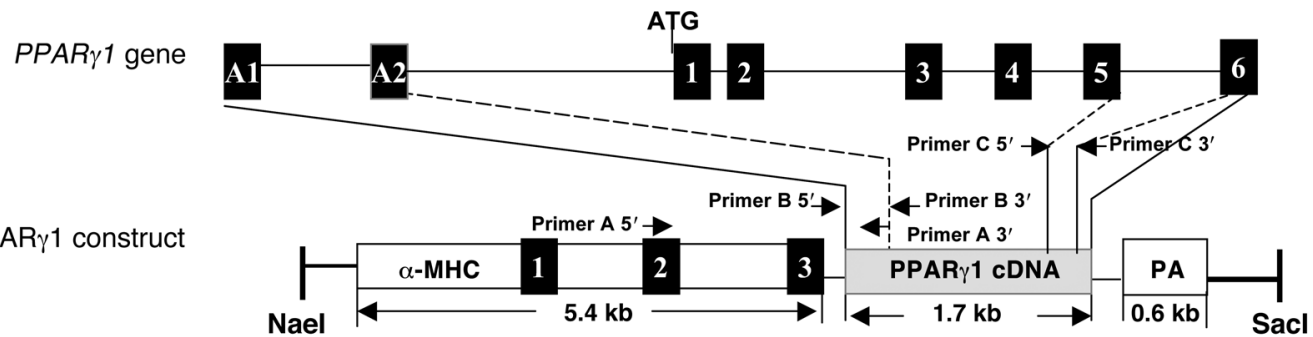

B

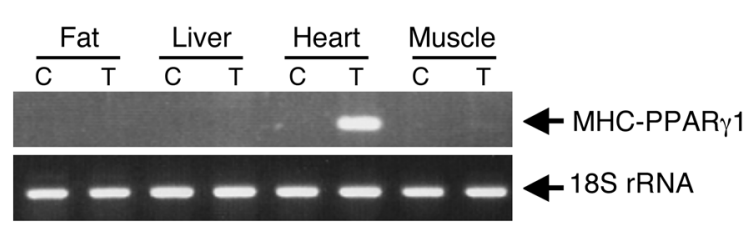

D

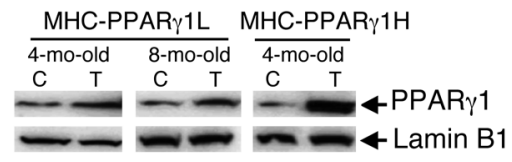

C

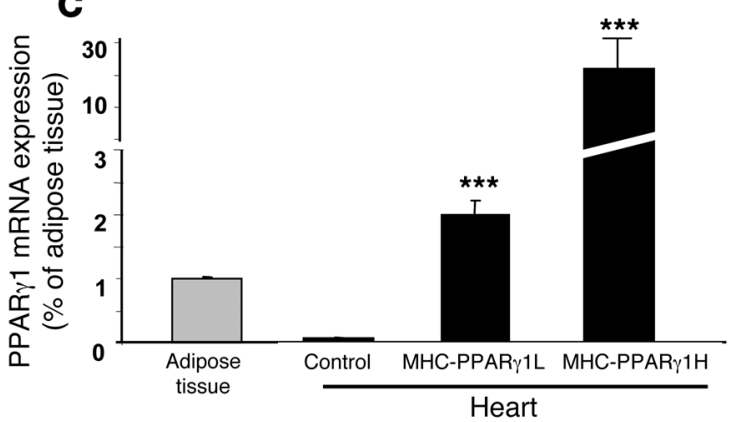

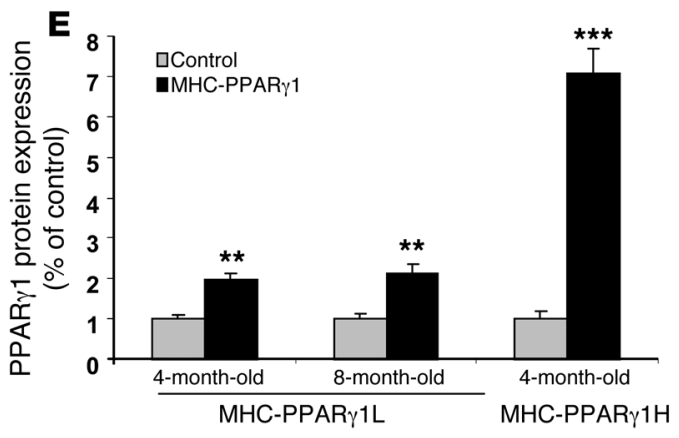

Figure 1

Construct and gene expression in PPAR $\gamma 1$-transgenic mice. (A) Diagram of PPAR $\gamma 1$ genomic locus and PPAR 1 construct design. The $\alpha-M H C$ promoter was used to drive PPAR 1 cDNA expression. Black boxes indicate exons that are numbered. PCR primers are indicated. Boxes A1 and A2 indicate PPAR 1 -specific exons. (B) Cardiac-specific MHC-PPAR 1 expression. RT-PCR analysis of RNA was performed in 3-monthold MHC-PPAR $1 \mathrm{~L}$ male mice using primer A: $5^{\prime}$ end specific to $\alpha-\mathrm{MHC}$ promoter exon 2 and $3^{\prime}$ end specific to PPAR $1 \mathrm{cDNA}$ nucleotides 173-192. (C) Heart expression of total PPAR $\gamma$ mRNA (both endogenous gene and transgene) in MHC-PPAR $\gamma 1 \mathrm{~L}$ and MHC-PPAR $\gamma 1 \mathrm{H}$ male mice was quantified by qRT-PCR. Primer $C$ was used for PCR amplification. Data are shown as mean ratio $( \pm S D ; n=5$ in each group) corrected for 18S rRNA. ${ }^{* * *} P<0.001$ for MHC-PPAR 1 mice versus control mice. (D) Nuclear protein $(30 \mu \mathrm{g})$ from heart tissues of 4- and 8-month-old MHCPPAR $\gamma 1 \mathrm{~L}$ and 4-month-old MHC-PPAR $\gamma 1 \mathrm{H}$ mice and their littermate controls was analyzed by Western blot using polyclonal PPAR $\gamma$ antibody. Western blot for lamin B1 is shown as a control. (E) Bands were quantified using Molecular Analysis Software. Data were normalized to values for littermate controls (set at 1.0), and normalized units of expression are shown ( \pm SD; $n=3$ in each group). ${ }^{* *} P<0.01$; ${ }^{* * *} P<0.001$ for MHCPPAR 1 versus control mice. C, littermate control; Tg, transgenic MHC-PPAR 1 mouse; PA, poly(A) site.

Transgenic mice from each of the lines bred normally, and glucose, body weight, and plasma lipid levels were similar to those of nontransgenic mice (Supplemental Table 1; supplemental material available online with this article; doi:10.1172/JCI30335DS1).

PPAR $\gamma$ activity in hearts of MHC-PPAR 1 mice. We estimated the degree of PPAR $\gamma$ activity in the MHC-PPAR $\gamma 1$ mice by assessing expression of downstream genes. Surprisingly, despite the adipose-like PPAR $\gamma 1$ expression level, hearts from young MHCPPAR $\gamma 1 \mathrm{~L}$ mice (4 months old) had an expression of downstream genes similar to that of controls (Figure 2A). Eight-month-old MHC-PPAR $\gamma 1 \mathrm{~L}$ mice, however, had greater expression of acylCoA oxidase (AOX) (1.35-fold), carnitine palmitoyl transferase-1 (CPT1) (1.63-fold), FA translocase (CD36) (1.61-fold), FA synthase (FAS) (1.44-fold), and adipose differentiation-related protein (ADRP) (1.81-fold) (Figure 2B).

In contrast, multiple genes were markedly upregulated in the hearts of 4-month-old MHC-PPAR $\gamma 1 \mathrm{H}$ mice (Figure 2C), including genes involved in lipid oxidation, uptake, synthesis, and storage, such as $A O X, C P T 1, C D 36, F A S, A D R P$, and SREBP1. Expression of ATP-binding cassette transport A1 (ABCA1), which mediates reverse cholesterol transport to apoA-I and is induced by PPAR $\gamma$ (18), was 1.73-fold higher in 4-month-old MHCPPAR $\gamma 1 \mathrm{H}$ mice (Figure 2C).

PPAR gene expression in control and MHC-PPAR $\gamma$ mice with aging. To determine why the MHC-PPAR $\gamma \mathrm{L}$ transgene did not alter downstream gene expression in the young mice, we assessed expression of PPAR family members in control and transgenic mice with aging. As noted by others (19), PPAR $\alpha$ expression decreased as the mice aged (Supplemental Figure 1A). Moreover, expression of PPAR $\alpha$ was reduced by $29 \%$ and $60 \%$ in the 2 - and 9 -month-old MHC-PPAR $\gamma$ L transgenic mice, respectively, compared with their littermate controls. Neither endogenous and transgenic PPAR $\gamma 1$ nor PPAR $\delta$ expression differed between 2- and 9-month-old mouse hearts (Supplemental Figure 1, B and C). Thus, changes in PPAR $\alpha$ expression might modify the downstream effects of the MHC-PPAR $\gamma \mathrm{L}$ transgene.

Cardiac lipid content and uptake in MHC-PPAR 1 mice. Greater CD36 expression in the MHC-PPAR $\gamma 1$ mice could increase uptake of plasma free and lipoprotein-derived FA. Heart TG and FA content were increased in 8-month-old MHC-PPAR $\gamma 1 \mathrm{~L}$ mice (Figure 3A). Oil red 

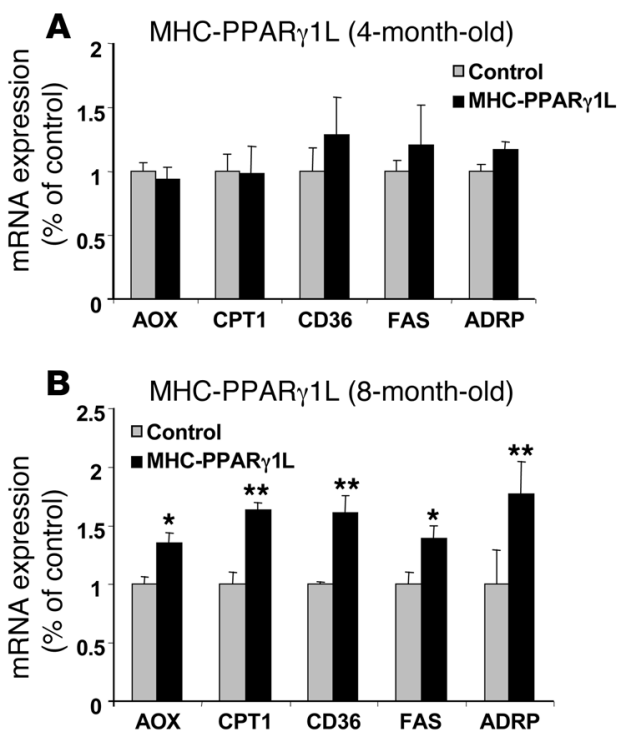

C

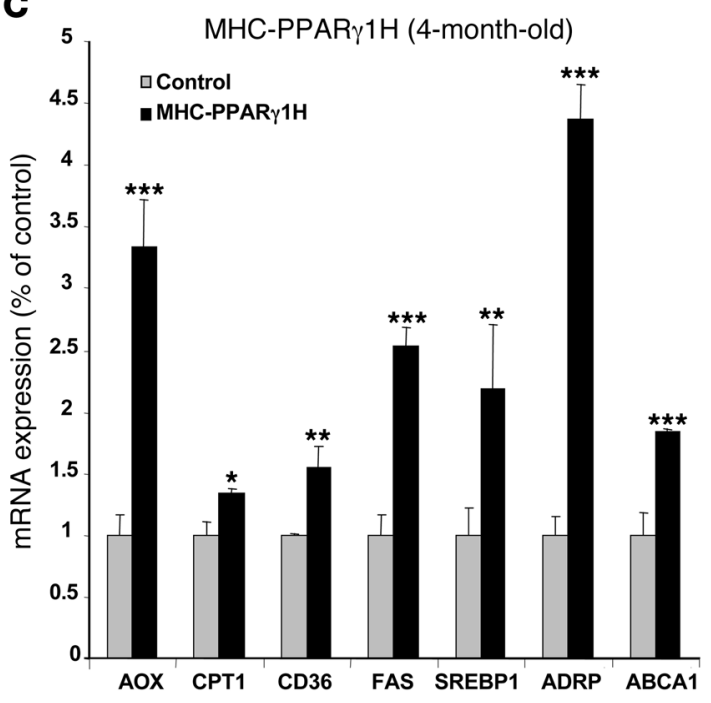

Figure 2

Expression of PPAR y target genes in the hearts of MHCPPAR 1 mice. (A and $\mathbf{B}$ ) Four- and 8-month-old MHCPPAR $1 \mathrm{~L}$ male mice; (C) 4-month-old PPAR $\gamma 1 \mathrm{H}$ male mice. Data are shown as mean ratio $( \pm \mathrm{SD} ; n=5-9$ in each group) corrected for $18 \mathrm{~S}$ rRNA and normalized to those for littermate controls (set as 1.0). ${ }^{*} P<0.05,{ }^{* *} P<0.01$, ${ }^{* * *} P<0.001$ for MHCPPAR 1 mice versus littermate controls.
O staining revealed greater accumulation of intracellular neutral lipids in hearts from MHC-PPAR $\gamma 1 \mathrm{~L}$ mice compared with littermate controls (Figure 3, B and C). Electron microscopy showed more lipid droplets within the sarcoplasm of cardiomyocytes, with distortion of the mitochondrial contours in MHC-PPAR $\gamma 1 \mathrm{~L}$ mice (Figure 3D). In some areas the cristae were disrupted (Figure 3E).

Cardiac uptake of VLDL-TG in 8-month-old MHC-PPAR $\gamma 1 \mathrm{~L}$ hearts was $74 \%$ greater than that in littermate control hearts $(P<0.01$; Figure 3F), which corresponds with increased expression of lipid uptake genes and cardiac lipid storage. Liver and skeletal muscle lipid uptake were not altered by the PPAR $\gamma 1$ transgene (data not shown).

Glucose transporter 4 expression and glucose uptake in MHC-PPAR 1 mice. Unlike in MHC-PPAR $\alpha$ transgenic mice (8), glucose transporter 4 (GLUT4) and GLUT1 mRNA levels were unchanged in the MHC-PPAR $\gamma 1 \mathrm{~L}$ mice (data not shown) and were upregulated in MHC-PPAR $\gamma 1 \mathrm{H}$ mice (Table 1). Pyruvate dehydrogenase kinase 4, the gene regulating glucose oxidation, was also downregulated in the MHC-PPAR $\gamma 1 \mathrm{H}$ mice (Table 1).

The GLUT4 gene undergoes a complex program of gene regulation. The GLUT4-myocyte enhancer factor 2 (GLUT4-MEF2) site is required for metabolic regulation of GLUT4 transcription (20-22). MEF2A, MEF2C, and MEF2D isoforms, but not MEF2B isoforms, are expressed in the heart. PPAR $\gamma$ coactivator 1 (PGC1) also interacts with MEF2C to upregulate endogenous GLUT4 expression and glucose uptake in cultured muscle cells (23). GLUT4 expression in MHC-PPAR $\gamma 1 \mathrm{H}$ mice was associated with increased expression of MEF2C and MEF2D (1.48-fold, $P<0.001$, and 1.55-fold, $P=0.009$, respectively), but with no change in MEF2A. PGC1 $\beta$ gene expression was also upregulated (1.68-fold; $P=0.01)$ in the hearts of the MHC-PPAR $\gamma 1 \mathrm{H}$ mice (Table 1 ).

Myocardial glucose import in vivo was assessed using 2-deoxyD- $\left[{ }^{3} \mathrm{H}\right]$ glucose. Heart uptake of glucose was unchanged in the MHC-PPAR $\gamma 1 \mathrm{~L}$ hearts (Figure 4A, left panel) and was increased by $37 \%$ in MHC-PPAR $\gamma 1 \mathrm{H}$ mice compared with littermate controls $(P<0.05$; Figure 4A, right panel). The PAS technique revealed greater cardiac glycogen storage in MHC-PPAR $\gamma 1 \mathrm{~L}$ mice compared with littermate controls (Figure 4B). PAS diastase (PAS-D) completely removed the glycogen in cardiac sections (Figure 4C). These data indicate that in the MHC-PPAR $\gamma$ mice, although cardiac lipid uptake was elevated, glucose uptake was not reduced.

Cardiac function in MHC-PPAR $\gamma 1$ mice. Both MHC-PPAR $\gamma 1 \mathrm{~L}$ and MHC-PPAR $\gamma 1 \mathrm{H}$ hearts had dilated left ventricles and impaired systolic function. Heart to body weight ratios were increased in 8-month-old MHC-PPAR $\gamma 1 \mathrm{~L}$ and 4-month-old MHC-PPAR $\gamma 1 \mathrm{H}$ mice (Figure 5, A and B). The dilated cardiomyopathy phenotype was grossly visible (Figure 5, C and D) and also seen by echocardiography (Figure 5, E-J). Left ventricular systolic dimension was increased $(0.17 \pm 0.03$ versus $0.14 \pm 0.01 \mathrm{~cm} ; P=0.021)$, and fractional shortening was reduced from $53 \% \pm 3.6 \%$ to $48 \% \pm 5.2 \%$ $(P=0.036)$ by age 8 months in PPAR $\gamma 1 \mathrm{~L}$ mice (Figure $5, \mathrm{~F}$ and $\mathrm{G})$. The MHC-PPAR $\gamma 1 \mathrm{H}$ mice had more severe cardiac dysfunction. Four-month-old PPAR $\gamma 1 \mathrm{H}$ hearts had greater left ventricular systolic dimension $(0.28 \pm 0.02$ versus $0.17 \pm 0.03 ; P<0.001)$ and a greater reduction in fractional shortening (from $47.3 \% \pm 5.3 \%$ to $30.2 \% \pm 3.2 \% ; P<0.001$ ) (Figure 5, I and J).

Expression of heart failure marker genes brain-type natriuretic peptide (BNP) and atrial natriuretic factor (ANF), was increased in MHC-PPAR $\gamma 1$ mice (Table 2). These increases were seen by 4 months in the PPAR $\gamma 1 \mathrm{H}$ line but not until 8 months in the PPAR $\gamma 1 \mathrm{~L}$ line.

Effects of rosiglitazone in wild-type and MHC-PPAR 1 mice. In contrast to other lipotoxic heart models $(13,16,24)$, rosiglitazone treatment of 8-month-old MHC-PPAR $\gamma 1 \mathrm{~L}$ mice led to further deterioration of cardiac function: increased lipid accumulation, larger hearts, and decreased fractional shortening (Figure 6, A and B). This was associated with increased cardiac gene expression of CD36 and ADRP in rosiglitazone-treated MHC-PPAR $\gamma 1 \mathrm{~L}$ mice (Figure 6C). When wild-type mice were treated with rosiglitazone, cardiac expression of usual PPAR $\gamma$ downstream genes was paradoxically reduced in the 8-month-old mice (Figure 6C). Adipose tissue and muscle had increased CD36 expression after rosiglitazone treatment (Supplemental Figure 2).

Pathways leading to cardiac dysfunction in MHC-PPAR 1 mice. To explore potential mechanisms in the development of lipid-induced cardiomyopathy, we examined heart tissue for evidence of lipid accumulation triggering programmed cell death. Four-monthold MHC-PPAR $\gamma 1 \mathrm{H}$ mice had a $40 \%$ increase in levels of cardiac 

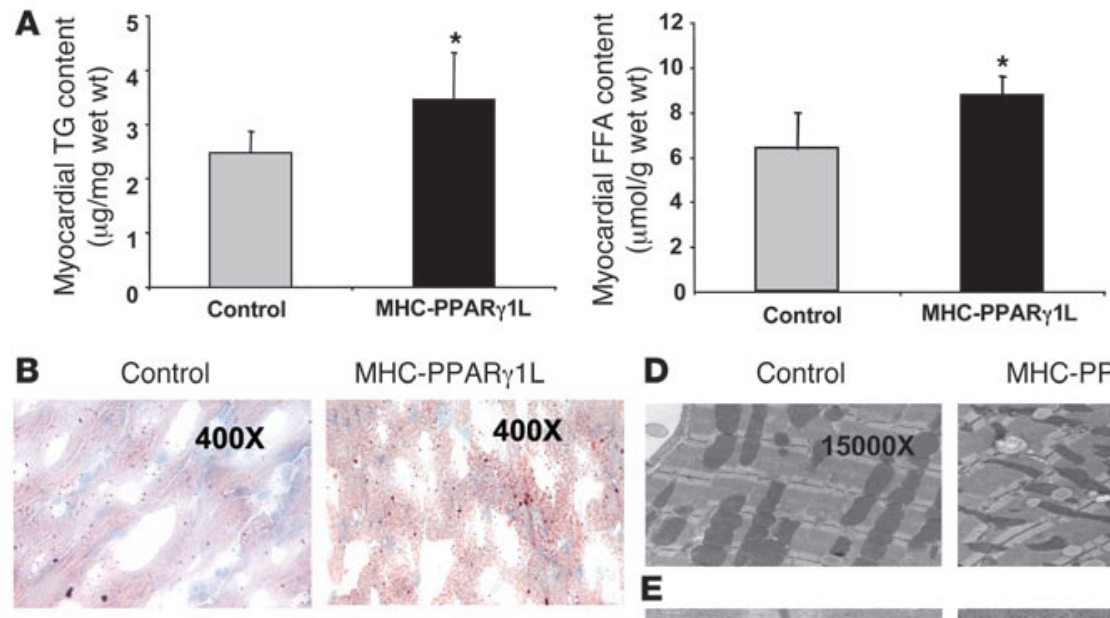

MHC-PPAR $\gamma 1 \mathrm{~L}$
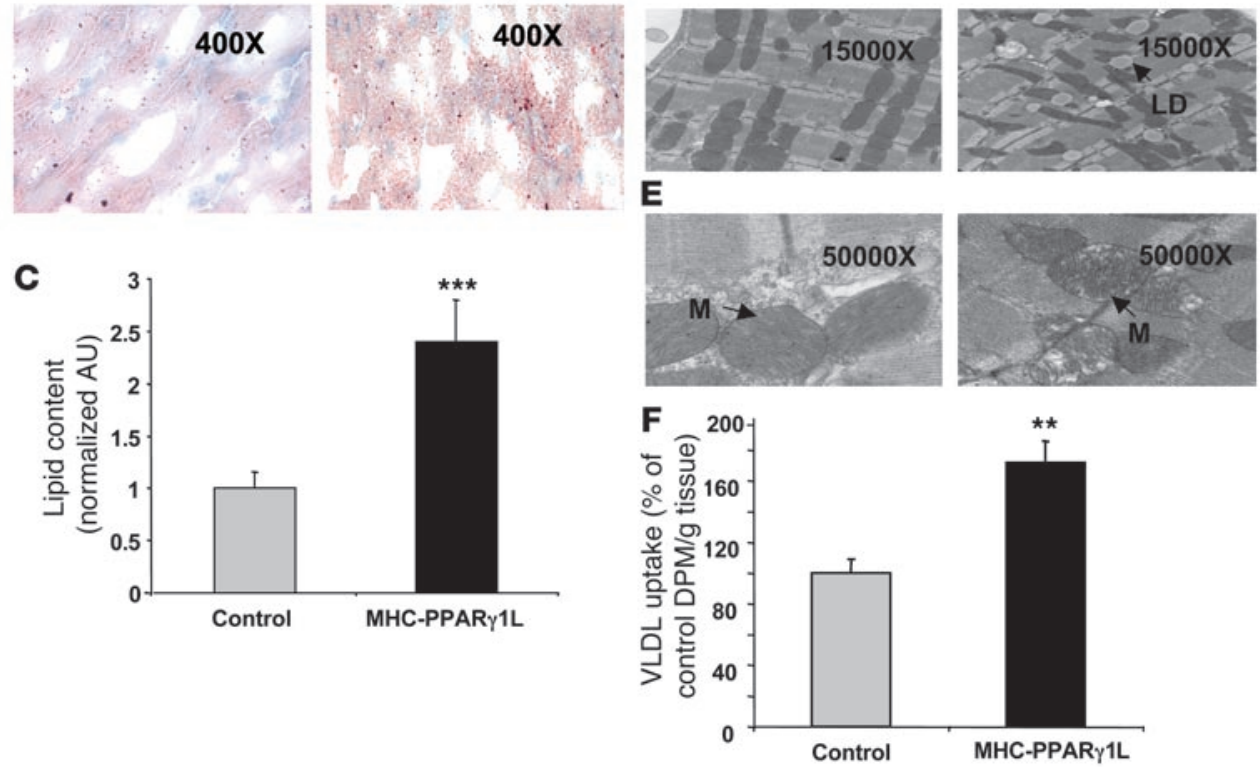

Figure 3

Increased heart lipid accumulation in MHC-PPAR 1 mice. (A) Heart TG (left panel) and FFA content (right panel) was significantly increased in MHC-PPAR $\gamma 1 \mathrm{~L}$ transgenic mice ( $n=7$ for each group). (B) Oil red O staining showed an abundance of neutral lipid droplets randomly scattered throughout the cytoplasm of cardiomyocytes in MHC-PPAR $\gamma 1 \mathrm{~L}$ female mice (right panel) after 24-hour fasting (original magnification, $\times 400$ ). (C) Oil red O staining was quantified using Molecular Analysis Software ( $n=3$ in each group). Data were normalized to values for littermate controls (set as 1.0). (D). Electron micrographs (original magnification, $\times 15,000$ ) of myocardial tissue showed a large increase in lipid droplets within the sarcoplasm of cardiomyocytes in MHC-PPAR $\gamma 1 \mathrm{~L}$ male mice (right panel) compared with littermates (left panel). All of these lipid droplets were located adjacent to mitochondria, with distortion of the mitochondrial contours. (E) Electron micrographs (original magnification, $\times 50,000)$ detailed distorted architecture of the mitochondrial inner matrix with electron lucent foci (arrows) in MHC-PPAR $1 \mathrm{~L}$ mice, and in some areas the cristae were disrupted. (F) $\left[{ }^{14} \mathrm{C}-\mathrm{TG}\right] \mathrm{VLDL}$ uptake into heart of MHC-PPAR $\gamma 1 \mathrm{~L}$ male mice and littermate control mice at 8 months of age ( $n=6$ per group). LD, lipid droplet; $\mathrm{M}$, mitochondria. Data are shown as mean $\pm \mathrm{SD}$. ${ }^{\star} P<0.05,{ }^{\star \star} P<0.01,{ }^{\star \star \star} P<0.001$ compared with littermate controls. DPM, decays per minute.

ceramide, a lipid capable of inducing apoptosis (25), compared with littermate controls (Figure 7A). This was associated with increased expression of long chain base 1 (LCB1) and LCB2, the subunits of serine palmitoyl-CoA transferase. Expression of apoptosis-related genes - B cell leukemia/lymphoma 2 (Bcl2), Bcl-2-like protein (Bcl-XL), BCL2-associated X protein (Bax), and caspase-9 - also dramatically increased (Figure 7B). The CCAAT/enhancerbinding protein $(\mathrm{C} / \mathrm{EBP})$ homologous protein $(\mathrm{CHOP})$, one of the regulators of ER stress-mediated cell death, was upregulated in the MHC-PPAR $\gamma 1 \mathrm{H}$ mice. iNOS was unchanged. There was evidence of positive TUNEL staining of heart tissue in both MHC-PPAR $\gamma 1 \mathrm{~L}$ and MHC-PPAR $\gamma 1 \mathrm{H}$, but not control, hearts (Figure 7, C and D).

PPAR 1 expression in bumans and streptozotocin-induced diabetic mouse hearts. We then tested whether PPAR $\gamma$ expression could be induced in the hearts of diabetic mice. Hearts of diabetic mice had 2.1-fold higher expression of PPAR $\gamma$ than those of control mice
$(P=0.003)$ (Figure 8A). We also assessed PPAR $\gamma$ expression in hearts from humans. Human hearts had 8.1- to 14.5-fold higher PPAR $\gamma$ mRNA levels than mouse hearts (Figure 8B). These data suggest that PPAR $\gamma$ is more functional in human hearts.

\section{Discussion}

Of the 3 members of the PPAR family of transcription factors, PPAR $y$ is expressed at the lowest level in the heart. However, recent studies of cardiac-specific PPAR $\gamma$-knockout mice have shown a role for this transcription factor in maintaining normal heart function (4). PPAR $\gamma$ has several well-documented effects to alter glucose and lipid metabolism in tissues. In both the adipose tissue $(26,27)$ and liver $(28)$, this transcription factor increases uptake of both glucose and lipid and increases storage of TG.

To study the pharmacologic actions of PPARs, these transcription factors, either alone or in the presence of their potent agonist 
Table 1

Expression of glucose metabolism and GLUT4 regulation genes in 4-month-old MHC-PPAR $1 \mathrm{H}$ mice

\begin{tabular}{lccc}
\hline & Gene & Control & MHC-PPAR $\gamma$ 1H \\
Glucose metabolism & & & \\
& GLUT4 & $1.0 \pm 0.10$ & $2.92 \pm 0.16^{\mathrm{A}}$ \\
& GLUT1 & $1.0 \pm 0.15$ & $2.09 \pm 0.21^{\mathrm{B}}$ \\
& PDK4 & $1.0 \pm 0.30$ & $0.40 \pm 0.08^{\mathrm{B}}$ \\
GLUT4 regulation & & & \\
& MEF2C & $1.0 \pm 0.06$ & $1.48 \pm 0.04^{\mathrm{A}}$ \\
& MEF2D & $1.0 \pm 0.05$ & $1.55 \pm 0.21^{\mathrm{B}}$ \\
& MEF2A & $1.0 \pm 0.13$ & $0.89 \pm 0.09$ \\
& PGC1 $\beta$ & $1.0 \pm 0.50$ & $1.68 \pm 0.23^{\mathrm{C}}$
\end{tabular}

Four-month-old male mice were fed a chow diet ( $n=8-9$ per group). Data are shown as mean ratio $( \pm S D)$ corrected for $18 \mathrm{~S}$ rRNA and normalized to values for littermate controls (set as 1.0). PDK4, pyruvate dehydrogenase kinase 4 . ${ }^{A} P<0.001,{ }^{B} P<0.01$, and ${ }^{C} P<0.05$ for MHC-PPAR $\gamma 1 \mathrm{H}$ mice versus littermate controls.

VP16 (29), have been transgenically expressed within a tissue. Our objective was to study actions of PPAR $\gamma$ only in the heart and to determine whether exogenous ligands modulate its activity; this was necessary to differentiate local from systemic actions of PPAR agonists. We created several lines of PPAR $\gamma$-transgenic mice to assess PPAR $\gamma$ function specifically in cardiomyocytes. In the lowexpressing line, no downstream changes in cardiomyocyte genes were found in young animals. The effects of PPAR $\gamma$ activation were noted only in older MHC-PPAR $\gamma 1 \mathrm{~L}$ mice. In contrast, in the MHCPPAR $\gamma 1 \mathrm{H}$ line, increased expression of PPAR $\gamma$ downstream genes was seen in young mice. Expression of lipid oxidation and uptake genes was increased, glucose uptake was not reduced, and lipotoxicity with cardiac dilation and dysfunction ensued. Thus, cardiac glucolipotoxicity was created.

The 2 lines of PPAR $\gamma 1$-transgenic mice showed a similar phenotype, but the timing and severity differed. Young MHC-PPAR $\gamma 1 \mathrm{~L}$ mice had no obvious changes in PPAR $\gamma$ downstream genes such as CD36, ADRP, and CPT1, even though PPAR $\gamma$ was expressed in hearts at levels comparable to those in

\section{Figure 4}

Increased cardiac glucose uptake and glycogen storage in MHC-PPAR 1 male mice. (A) 2-Deoxy-D-[ $\left.{ }^{3} \mathrm{H}\right]$ glucose uptake into heart of MHC-PPAR $\gamma 1$ and wild-type control mice. MHC-PPAR $\gamma 1 \mathrm{~L}$ mice were 8 months old $(n=7$ in each group); MHC-PPAR $\gamma 1 \mathrm{H}$ mice were 4 months old ( $n=6$ in each group). (B) PAS staining of heart tissue from 8-month-old MHC-PPAR $\gamma 1 \mathrm{~L}$ female mice (middle panel) and littermate controls (left panel) after 6 -hour fasting (original magnification, $\times 400$ ). The arrow shows focal increased staining. Glycogen content was quantified using Molecular Analysis software $(n=3-4$ per group) and normalized to values for PAS-staining controls (set as 1.0) (right panel). G, glycogen. Data are shown as mean $\pm \mathrm{SD}$. ${ }^{*} P<0.05$ compared with littermate controls; ${ }^{* *} P<0.01$. (C) The glycogen staining was removed by PAS diastase (PAS-D) digestion (left and middle panels), and the data were quantified using Molecular Analysis software (right panel).

$\mathbf{B}$ adipose tissue. This was quite surprising but in some ways echoed the lack of effect of cardiomyocyte PPAR $\gamma$ deficiency on expression of genes controlling lipid and glucose metabolism (4). We initially wondered whether a deficiency of agonist prevented the expected gene inductions. However, neither a high-fat diet nor rosiglitazone led to PPAR $\gamma$ activation in 4-month-old PPAR $\gamma 1 \mathrm{~L}$ mice (data not shown). We also noted that rosiglitazone treatment of wild-type mice reduced expression of PPAR $\gamma$ targets. We suspect that rosiglitazone redirected naturally occurring PPAR ligands to other tissues, especially adipose tissue. In another model of lipotoxicity, rosiglitazone decreased delivery of plasma lipids to the heart (13). In part, the lack of effect of the MHC-PPAR $\gamma 1 \mathrm{~L}$ transgene was due to the reduced heart expression of PPAR $\alpha$. It is of interest that tissues with the highest level of PPAR $\gamma$, i.e., the adipose tissue, have relatively low levels of PPAR $\alpha$ expression (30), whereas PPAR $\alpha$-rich tissues such as the heart have low levels of PPAR $\gamma$. The reasons for this are not clear, but our data suggest that there is a reciprocal regulation of PPAR transcription factors.

With aging, the actions of the MHC-PPAR $\gamma \mathrm{L}$ transgene became apparent: expression of genes involved in both FA uptake and oxidation increased, and the hearts accumulated TG. The hearts were dilated, had decreased ejection fraction, and expressed higher levels of failure markers (BNP and ANF). Other models of cardiac dysfunction show greater pathology with aging. With aging, hearts shift to greater glucose and less FA use even in the absence of any cardiac pathology (31). Perhaps if a similar process occurs in mice, more PPAR $\gamma$ ligands that are normally oxidized might accumulate in older PPAR $\gamma 1 \mathrm{~L}$ hearts. Alternatively, the age-related decline in PPAR $\alpha$ expression (19) might allow more ligands to bind to PPAR $\gamma$ and permit this transcription factor to associate with unoccupied PPAR response elements.

In contrast to the lack of effect in MHC-PPAR $\gamma 1 \mathrm{~L}$ young mice, the MHC-PPAR $\gamma 1 \mathrm{H}$ line had gene changes and evidence of cardiac dysfunction by 2 months. The severe dilated cardiomyopathy in these animals led to $100 \%$ mortality by 5 months (Supplemental Figure 3E).
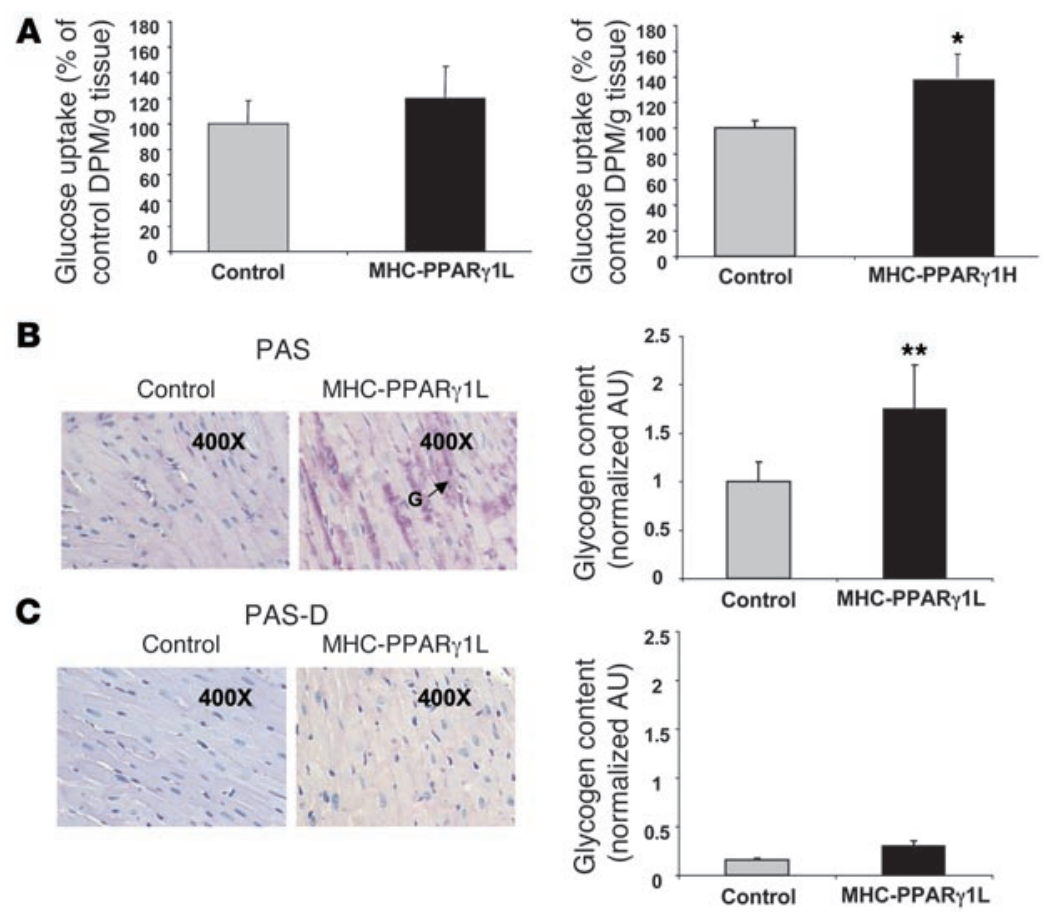
A
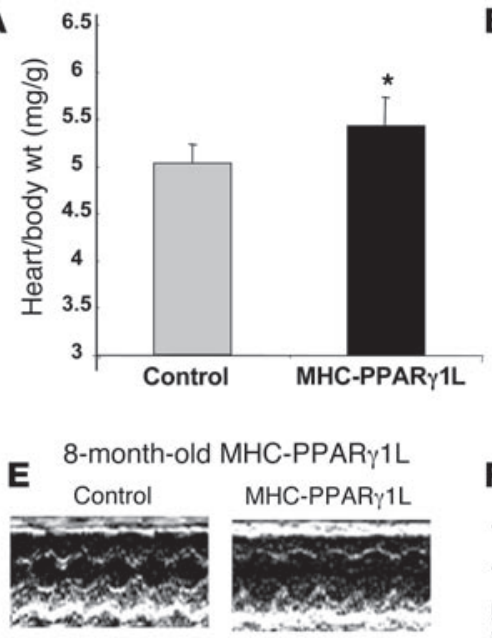

H

4-month-old MHC-PPAR $1 \mathrm{H}$

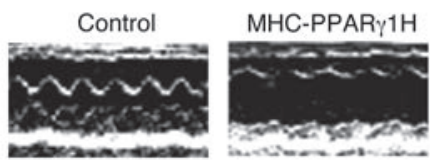

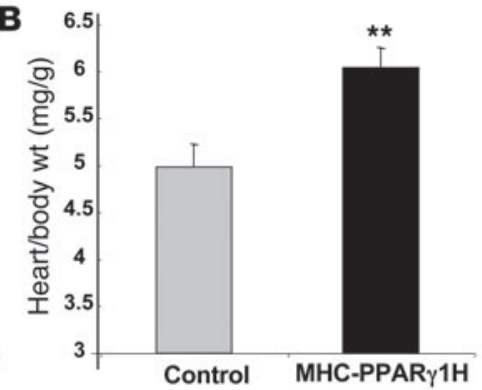

C

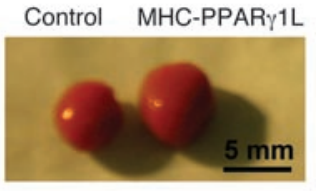

D

Control MHC-PPAR 11 L

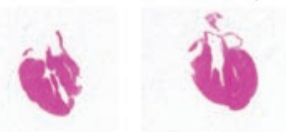

8-month-old MHC-PPAR $\gamma 1 \mathrm{~L}$
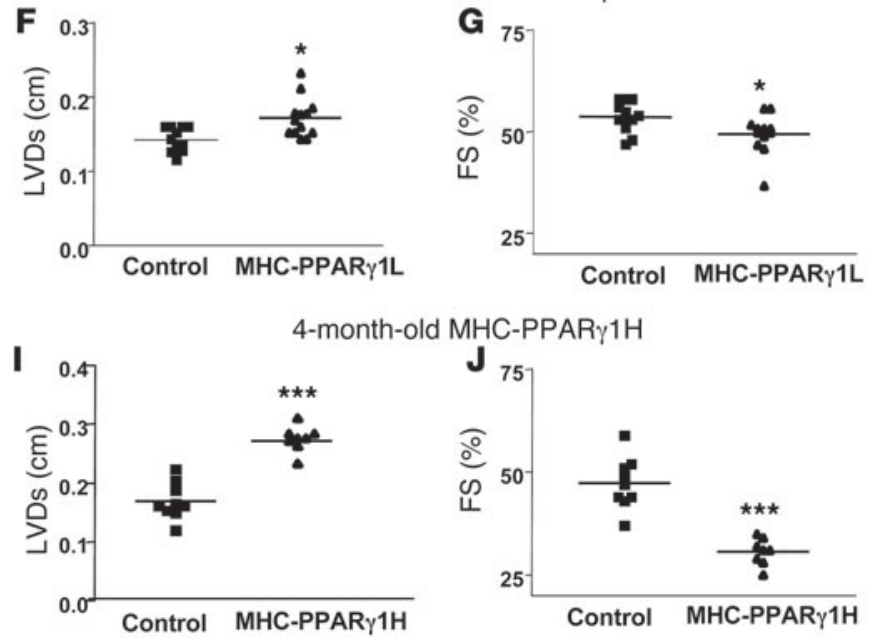

Figure 5

Dilated cardiomyopathy in MHC-PPAR 1 mice. (A and B) The heart to body weight ratio was increased in both MHC-PPAR $1 \mathrm{~L}(n=11-13)$ and MHC-PPAR $\gamma 1 \mathrm{H}$ male mice $(n=8-9)$. (C) Representative photographs of hearts of control and MHC-PPAR $1 \mathrm{~L}$ male mice. (D) Histological section of H\&E-stained cardiac tissue in control and MHC-PPAR $1 \mathrm{~L}$ male mice. (E and $\mathbf{H}$ ) Representative echocardiographic images of left ventricle motion in MHC-PPAR $\gamma 1 \mathrm{~L}$ and MHC-PPAR $1 \mathrm{H}$ mice. Echocardiography showed increased left ventricular systolic dimension (F and I) and reduced fractional shortening (G and $\mathbf{J})$ in both MHC-PPAR $1 \mathrm{~L}$ and MHC-PPAR $\gamma 1 \mathrm{H}$ mice. FS, fractional shortening; LVDs, left ventricular end-systolic dimension. Data are shown as mean $\pm \mathrm{SD} .{ }^{*} P<0.05,{ }^{* *} P<0.01$, and ${ }^{* *} P<0.001$ versus littermate controls.

We performed several studies to quantify the in vivo uptake of substrates in the PPAR $\gamma 1$ mice. More FAs derived from VLDLTG were found in PPAR $\gamma 1$ hearts. Cardiac glucose uptake and GLUT4 expression were either not reduced (PPAR $\gamma 1 \mathrm{~L})$ or were increased (PPAR $\gamma 1 \mathrm{H})$. This was associated with greater storage of glycogen. These studies contrast with and parallel those found with cardiac overexpression of PPAR $\alpha$ (8). MHC-PPAR $\alpha$ transgenic mice also have dilated lipotoxic cardiomyopathy. Cardiomyocyte PPAR $\alpha$ induced FA oxidation (e.g., AOX and CPT1) and FA uptake genes (CD36). This likely contributed to the increased cardiac lipid in the setting of greater oxidation. In contrast to MHC-PPAR $\gamma 1$ mice, MHC-PPAR $\alpha$ mice had a marked reduction in GLUT4 expression and cardiac glucose uptake (8). Thus, PPAR $\gamma$ and PPAR $\alpha$ increased the expression of genes for FA oxidation and uptake and caused TG accumulation but differed in their effects on glucose metabolism.

Under normal physiologic conditions, the heart utilizes FAs as its chief energy substrate. Because there is limited capacity for TG storage in the cardiomyocyte, the uptake and oxidation of FAs are tightly coupled. Both increased FA delivery and impaired FA oxidation result in intramyocardial TG accumulation and lipotoxicity. The etiology of heart dysfunction in diabetes and severe obesity is thought to involve lipotoxicity (32).

Reduced cardiac function has been attributed to accumulation of toxic lipids (33), increased FA oxidation, and/or reduced glucose utilization. Reductions in glucose uptake and oxidation 4-month-old Control

$B N P$

$1.00 \pm 0.29$

MHC-PPAR $\gamma 1 \mathrm{~L} \quad$ MHC-PPAR $\gamma 1 \mathrm{H}$

ANF $\quad 1.00 \pm 0.53 \quad 1.23 \pm 0.42 \quad 12.9 \pm 2.60^{A}$

Male mice were fed a chow diet ( $n=4-7$ per group). Data are shown as mean ratio $( \pm \mathrm{SD})$ corrected for $18 \mathrm{~S}$ rRNA and normalized to values for littermate controls (set as 1.0). $\mathrm{A} P<0.001$ and ${ }^{\mathrm{B} P}<0.01$ for MHC-PPAR $\gamma 1$ mice versus littermate controls. 
A

A MHC-PPAR $11 \mathrm{~L}$

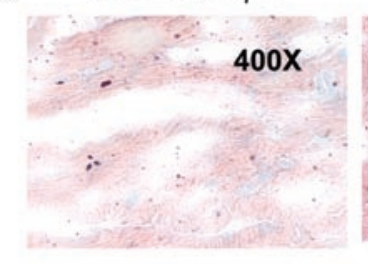

B
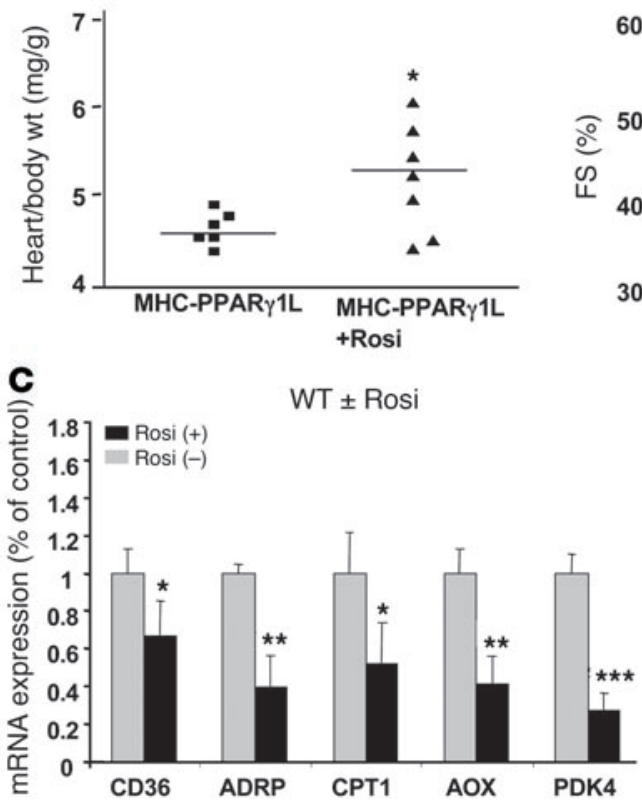

MHC-PPAR $\gamma 1 L+$ Rosi

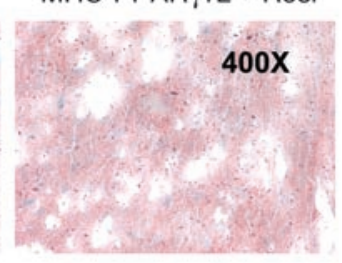

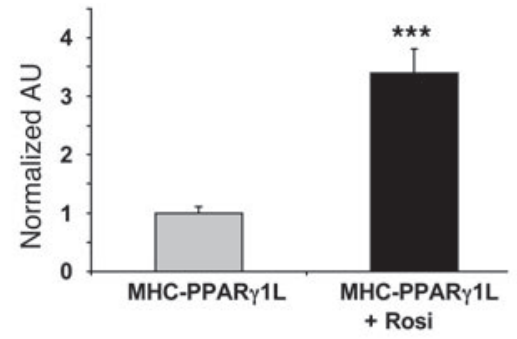
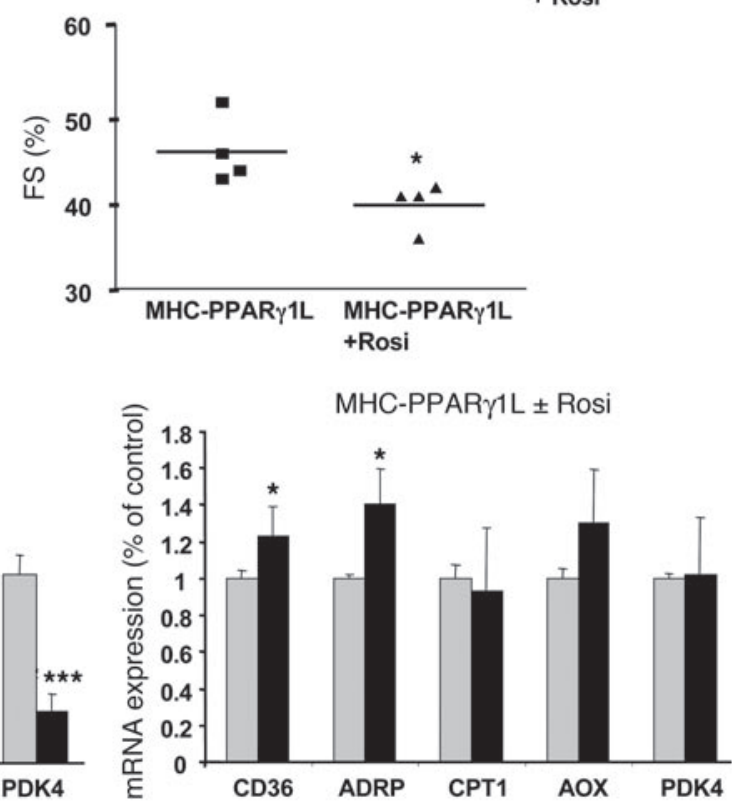

Figure 6

MHC-PPAR $1 \mathrm{~L}$ and C57BL/6 wild-type mice with or without rosiglitazone treatment. (A) Oil red O heart histology of 8-month-old MHC-PPAR $\gamma 1 \mathrm{~L}$ female mice with (middle panel) or without (left panel) rosiglitazone treatment. Staining was quantified and normalized to values for littermate controls (set as 1.0) (right panel). Data are shown as mean ( $\pm \mathrm{SD} ; n=3-4$ in each group). (B) Heart to body weight ratio (left panel) and echocardiographic measurements of fractional shortening (right panel) in 8-month-old MHC-PPAR $\gamma 1 \mathrm{~L}$ male mice with or without rosiglitazone treatment. (C) qRT-PCR analysis of cardiac gene expression in 8-month-old male C57BL/6 wild-type (left panel) and MHC-PPAR $\gamma 1 \mathrm{~L}$ mice (right panel) with or without rosiglitazone treatment $\left(n=6-7\right.$ per group). ${ }^{\star} P<0.05,{ }^{* \star} P<0.01$, and ${ }^{* \star *} P<0.001$ versus the group without rosiglitazone treatment group. Rosi, rosiglitazone, WT, wild-type C57BL/6 mice.

alone are associated with cardiac dysfunction; this is especially the case under ischemic conditions (32). GLUT4 mRNA levels are reduced in several models of cardiac lipotoxicity $(8,34)$ and with streptozotocin-induced diabetes $(35,36)$. However, the development of lipotoxic dilated cardiomyopathy in the MHC-PPAR $\gamma 1$ mice is not the result of defective glucose uptake. Thus, alterations in lipid metabolism, and not reduced glucose utilization, are likely to be the primary cause of heart dysfunction in the MHCPPAR $\gamma 1$ mice and other lipotoxic models.

A number of factors, including MEF2 $(20,22)$ and PGC1 $\beta(23)$, regulate GLUT4 gene expression in skeletal muscle, adipose tissue, and heart. In one study, MEF2A, but not MEF2D, was associated with increased cardiac expression of GLUT4 (37). In our mice, cardiac expression of PPAR $\gamma$ was associated with upregulated MEF2C, MEF2D, and PGC-1 $\beta$ but not MEF2A. Others have suggested that PPAR $\gamma$ alone upregulates GLUT4 expression (38).

At first glance our results appear to conflict with the beneficial effects of PPAR $\gamma$ agonist treatment of animals and perfused hearts been shown to correct the lipotoxicity leading to skeletal muscle insulin resistance in mice fed a high-fat diet (39). Ceramide has been suggested to lead to apoptosis in some cells (40).

ER stress, which is associated with FA excess and was increased in both lines of MHC-PPAR $\gamma 1$ mice (33), is a cellular response triggered by disruption of the ER homeostasis and consequent accumulation of misfolded proteins in its lumen. To date, several proteins involved in ER stress-induced apoptosis have been identified, including CHOP and Bcl-2 family members (41). CHOP is a transcription factor of the C/EBP family. Its basal expression is low under nonstressed conditions, but it increases markedly in response to physiological and pharmacological stresses (42). Upregulation of CHOP expression indicates that the ER stress-mediated apoptosis pathway was involved in the MHC-PPAR $\gamma$ mouse hearts.

In our MHC-PPAR $\gamma$ mouse hearts, there was evidence of cellular apoptosis; some proapoptotic genes were induced (Bax and caspase-9), but expression of some antiapoptotic genes also increased 
A

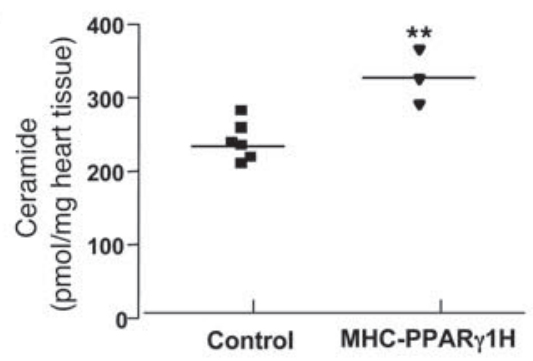

B

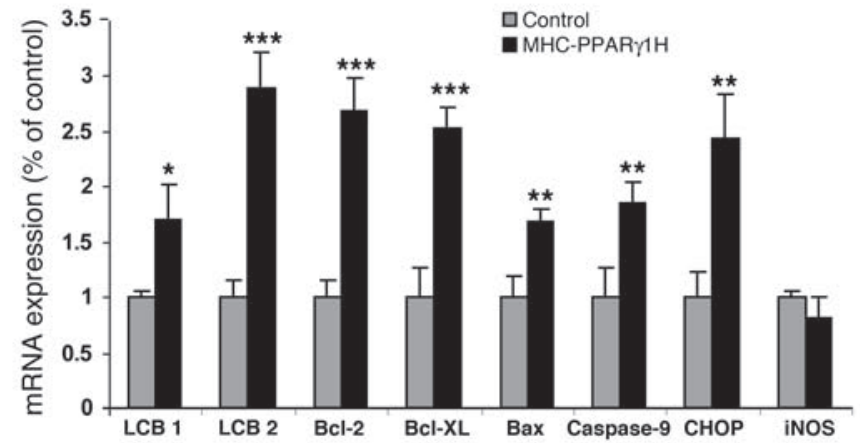

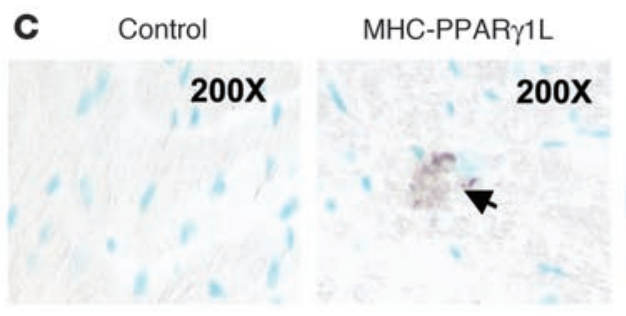
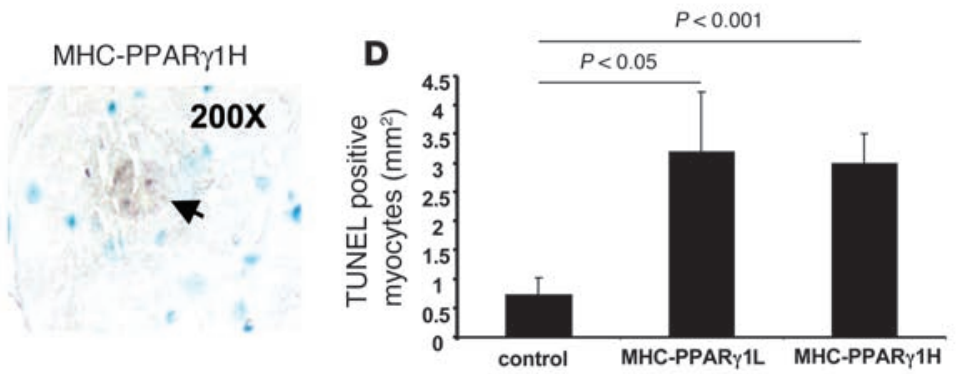

Figure 7

Lipoapoptosis in MHC-PPAR $\gamma 1$ hearts. (A) Cardiac ceramide was measured in heart tissue from 4-month-old MHC-PPAR $\gamma \mathrm{H}$ male mice and their littermate controls using diacylglycerol kinase assay and normalized for tissue weight $(n=3-6)$. (B) Ceramide synthesis genes (LCB1 and LCB2), ER stress-induced apoptosis-related gene (CHOP), and apoptosis genes (Bax and caspase-9) were upregulated in MHC-PPAR $1 \mathrm{H}$ male mice hearts. Antiapoptosis genes Bcl2 and Bcl-XL were also upregulated $(n=8-9)$. (C) Cardiac ventricular tissues from control (left panel) and 8-month-old MHC-PPAR $\gamma 1 \mathrm{~L}$ (middle panel) and 4-month-old MHC-PPAR $1 \mathrm{H}$ male mice (right panel) were stained for DNA fragmentation by a TUNEL protocol (original magnification, $\times 200$ ). Apoptotic cells containing fragmented nuclear chromatin exhibited a dark brown nuclear staining. (D) The TUNEL-positive myocytes were counted and expressed as the number of TUNEL-positive myocytes per millimeter squared tissue area. Data are shown as mean $( \pm \mathrm{SD}$ ) and normalized to values for littermate controls (set as 1.0$) .{ }^{*} P<0.05,{ }^{\star \star} P<0.01$, and ${ }^{\star \star \star} P<0.001$ versus littermate controls.

(Bcl2 and $\mathrm{Bcl}-\mathrm{XL})$. It appears likely that cardiac overexpression of PPAR $\gamma$ leading to either increased ceramide or ER stress triggered the intrinsic apoptosis-signaling pathway mediated by caspase- 9 but also induced survival signals.

PPAR $\gamma$ agonist treatment of humans is associated with peripheral edema and increased heart failure (43); this was seen in the recent PROactive (44) and Diabetes Reduction Assessment with Ramipril and Rosiglitazone Medication (DREAM) studies (45). In addition, the use of a potent PPAR $\alpha / \operatorname{PPAR} \gamma$ dual agonist caused cardiomyopathy and more heart failure (46). Tissue-specific deletion of PPAR $\gamma$ in the kidney reduced sodium uptake (47). Thus, it has been postulated that a side effect of PPAR $\gamma$ agonists is salt and water retention, a process that could lead to edema and heart failure (48). However, as has been noted by others (49), salt retention usually leads to hypertension; PPAR $\gamma$ agonists are associated with reduced blood pressure (44). Thus, the reasons for increased heart failure in some patients treated with these drugs may be complex and involve toxic effects of the drugs on the myocardium, a process found only in a minority of patients.

In summary, we have studied the actions of PPAR $\gamma 1$ directly in cardiomyocytes. As is known to occur in adipocytes, PPAR $\gamma$ expression increased both lipid and glucose uptake, the former by an increase in CD36 expression and the latter, in part, by upregulation of GLUT4. The ensuing dilated cardiomyopathy is due to glucolipotoxicity, as both TG and glycogen are inappropriately stored. Rosiglitazone, a PPAR $\gamma$ agonist, increased this toxicity but did not increase cardiac PPAR $\gamma$ downstream gene expression in wild-type mice. In part, this might be due to a redirection of normal PPAR $\gamma$ ligands to other tissues. PPAR $\gamma$ in the mouse heart is increased with streptozotocin-induced diabetes. In addition, this transcription factor is expressed at higher levels in human heart. It is possible that cardiotoxic effects of PPAR $\gamma$ agonists in humans occur due to glucolipotoxocity. Fortunately, this is seen in only a minority of patients whose diabetes and perhaps genetic variation make them unusually sensitive to what is otherwise a useful form of therapy.

\section{Methods}

Generation and identification of the MHC-PPAR $\gamma$ mice. Creation of the mice and all metabolic and genetic studies were reviewed and approved by the Columbia University Institutional Animal Care and Use Committee. A transgenic construct containing a 1.7-kb mouse PPAR $\gamma 1 \mathrm{cDNA}$, which differs from PPAR $\gamma 2$ by a lack of 30 additional $\mathrm{NH}_{2}$-terminal amino acids, was cloned downstream of the $\alpha$-MHC promoter $(5.4 \mathrm{~kb})$. Sac1 and Nae 1 digestion of MHC-PPAR $\gamma 1$ produced a linear $7.8-\mathrm{kb}$ fragment that was used for microinjection (Figure 1A). Transgenic mice were produced by microinjection of the MHC-PPAR $\gamma 1$ construct into fertilized 1-cell C57BL $/ 6 \times \mathrm{CBA} \mathrm{F}_{1}$ eggs. Founder mice and transgenic expression of PPAR $\gamma 1$ were identified by analysis of genomic DNA with primer A (5'-AGCTGTGGTCCACATTCTTC-3'; a sense primer specific to MHC promoter exon 2) and antisense primer (5'-AGAATGGCATCTCTGTGTC-3') specific to PPAR $\gamma 1$ cDNA nucleotides 173-192. PPAR $\gamma 1$ mRNA 

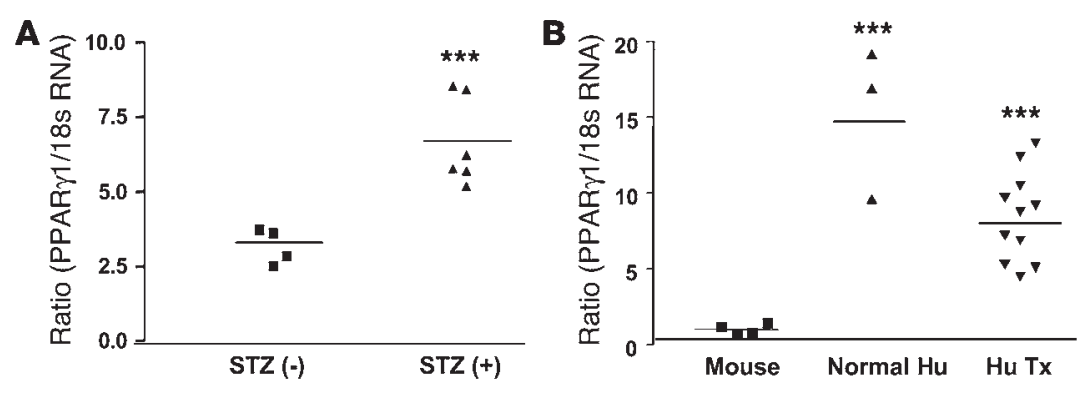

\section{Figure 8}

Upregulation of PPAR 1 expression in streptozotocin-induced diabetic mouse and humans hearts. (A) Four-month-old wild-type C57BL/6 male mice were treated with streptozotocin (STZ), and 3 weeks later hearts from control and diabetic mice (glucose $>300$ $\mathrm{mg} / \mathrm{dl}$ ) were harvested and PPAR 1 mRNA assayed by qRT-PCR. (B) Heart tissue was obtained from a normal individual (Normal $\mathrm{Hu}$ ) and from hearts of patients undergoing heart transplantation (Hu Tx). PPAR $\gamma 1$ and 18S rRNA were measured in human and wild type mouse mRNAs using primers that were common for human and mouse genes. ${ }^{\star \star \star} P<0.001$ versus mice group.

expression (both transgene and endogenous) in the heart was confirmed by RT-PCR with PPAR $\gamma 1$-specific primer B, sense: 5'-GAGTGTGACGACAAGATTTG-3', and antisense: 5'-GGTGGGCCAGAATGGCATCT-3'. To compare heart PPAR $\gamma$ expression with that of adipose tissue, we measured heart and adipose tissue PPAR $\gamma$ expression simultaneously using primers that were common to PPAR $\gamma 1$ and PPAR $\gamma 2$ (primer C, sense: 5'-ATCTACACGATGCTGGC-3', and antisense: 5'-GGATGTCCTCGATGGG-3') (Figure 1A).

Western blot analysis. Fresh heart tissues from 4- and 8-month-old MHCPPAR $\gamma 1 \mathrm{~L}$ and 4-month-old MHC-PPAR $\gamma 1 \mathrm{H}$ mice and their littermate controls were prepared and nuclear proteins were isolated using a nuclear extraction kit according to the manufacturer's instructions (Active Motif). Thirty micrograms of nuclear proteins were subjected to Western blot analysis with PPAR $\gamma$ antibody (sc-7196; 1:100 dilution; Santa Cruz Biotechnology Inc.). For control of protein loading, the blots were stripped and reacted with anti-lamin B1 antibody (gift from Howard Worman, Columbia University). Bands were quantified by densitometry using Molecular Analysis Software (Bio-Rad).

Heart and plasma lipids. Blood from fasted (6 hours) mice was collected from retro-orbital plexus for the measurement of plasma total cholesterol (TC), TG, and FFAs. To measure tissue lipids, hearts were perfused with PBS and homogenized in $4^{\circ} \mathrm{C}$ in $1 \mathrm{M} \mathrm{NaCl}$ buffer containing lipase inhibitors to prevent TG hydrolysis. Lipids were extracted from heart tissues (50 $\mathrm{mg}$ ) according to methods modified from that of Folch et al. (50). The dried lipids were solubilized in PBS containing $2 \%$ Triton X-100. Heart and plasma TC, TG, and FFA were measured enzymatically using an Infinity kit (Thermo Electron Corp.) and a NEFA C kit (Wako).

Tissue gene expression. Total RNA was prepared using a Pure Link Microto-Midi Total Purification System kit (Invitrogen). One microgram of RNA was initially treated with DNase I (Invitrogen) for 15 minutes. The RNA samples were then reverse transcribed using the ThermoScript RT-PCR Kit (Invitrogen). Real-time quantitative RT-PCR (qRT-PCR) was performed using an ABI 7700 (Applied Biosystems). Amplification was performed using SYBR Green PCR Master Mix (Applied Biosystems). Primers used for PCR amplification are listed in Supplemental Tables 2 and 3. Analysis was performed using Sequence Detection Software (Applied Biosciences). Standard curves were generated using undiluted and diluted (1:10, 1:100, and $1: 1,000)$ cDNA samples from heart tissue. Correlation coefficients were 0.98 or greater. Data were normalized with $18 \mathrm{~S}$ rRNA.
Histological analysis. Neutral lipids were assessed in hearts taken from 24-hour-fasted male and female mice perfused with PBS. The hearts were embedded in Tissue-Tek Optimal Cutting Temperature compound (Sakura). Midventricular sections of myocardium (6 $\mu \mathrm{M}$ in thickness) were stained with oil red $\mathrm{O}$ and counterstained with hematoxylin.

PAS and PAS-D staining were used to demonstrate heart glycogen. Hearts from 6-hour-fasted male and female mice were placed in $10 \%$ neutral buffered formalin. Midventricular sections were fixed in methyl alcohol for 10 minutes and stained with Schiff Reagent (Poly Scientific) and H\&E. The specificity of glycogen staining was demonstrated by treating heart sections with diastase of malt (Sigma-Aldrich), which removes the glycogen.

TUNEL staining. Cardiac ventricular tissues from 4- and 8-month-old MHC-PPAR $\gamma 1 \mathrm{~L}$ and 4-month-old MHC-PPAR $\gamma 1 \mathrm{H}$ were fixed in formalin, embedded in paraffin, and sectioned. Tissues were stained for DNA fragmentation by a TUNEL protocol according to the manufacturer's specifications (R\&D Systems). The data were quantified by counting TUNEL-positive myocytes per square millimeter cellular area.

Echocardiographic analysis. Two-dimensional echocardiography was performed in conscious mice using techniques described previously (Sonos 5500 system; Philips Medical Systems) (10). Two-dimensional echocardiographic images were obtained and recorded in a digital format. Images were than analyzed off-line by a researcher blinded to the murine genotype. Left ventricular end-diastolic dimension (LVDd) and left ventricular end-systolic dimension (LVDs) were measured. Percent fractional shortening was calculated as: \% FS $=([\mathrm{LVDd}-\mathrm{LVDs}] / \mathrm{LVDd}) \times 100$.

Electron microscopy. Left ventricles from 8-month-old mice were fixed with $2.5 \%$ glutaraldehyde in $0.1 \mathrm{M}$ Sorensen's buffer $(0.2 \mathrm{M}$ monobasic phosphate/0.2 M dibasic phosphate 1:4 vol/vol; $\mathrm{pH} 7.2$ ), postfixed in osmium tetroxide, and embedded in EPON 812 (Electron Microscopy Sciences). Ultrathin sections were stained with uranyl acetate and lead citrate and examined under a JEM-1200ExII electron microscope (JEOL).

Uptake of VLDL and glucose. Human VLDL was isolated from normal subjects by sequential ultracentrifugation and was labeled with [carboxyl$\left.{ }^{14} \mathrm{C}\right]$ triolein (PerkinElmer) via cholesterol ester transfer protein (CETP) as previously described (51). Sixteen-hour-fasted MHC-PPAR $\gamma 1$ mice and littermates were first injected intravenously with $1 \times 10^{6}$ decays per minute (DPM) of 2-deoxy-D- $\left[{ }^{3} \mathrm{H}\right]$ glucose (PerkinElmer). Fifty-five minutes after 2-deoxy-D-[ $\left[{ }^{3} \mathrm{H}\right]$ glucose injection, $1 \times 10^{6} \mathrm{DPM}$ of $\left[{ }^{14} \mathrm{C}\right.$-TG]VLDL was injected. Five minutes after VLDL injection, blood was collected, and the vasculature was thoroughly perfused with $10 \mathrm{ml}$ of PBS via cardiac puncture. Tissues were then excised, and accumulated radioactivity for $\left[{ }^{3} \mathrm{H}\right]$ glucose and $\left[{ }^{14} \mathrm{C}-\mathrm{TG}\right]$ VLDL was measured. Amounts of glucose and VLDL injected were adjusted by plasma radioactivity counts at 30 seconds after each injection and were compared with plasma counts at the end of the experiments. Tissue uptake for transgenic mice was compared with uptake of control littermate controls.

Ceramide content. Cardiac ceramide levels were determined using the diacylglyceride kinase method as described previously (52).

Human tissues. Normal human heart tissues were obtained from National Disease Research Interchange. Hearts from 11 orthotopic heart transplant recipients $(50.3 \pm 8.8$ years old) with idiopathic dilated cardiomyopathy were obtained from the Department of Surgery at Columbia University Medical Center (CUMC). The Institutional Review Board at CUMC approved all study protocols. Normal human left ventricle total RNA was purchased 
from Ambion (no. 5856). Human cardiac PPAR $\gamma 1$ mRNA expression was measured by qRT-PCR and normalized with human $18 \mathrm{~S}$ rRNA. Primer sequences used for qRT-PCR were shared by both mouse and human genes (Supplemental Table 3). BLAST (http://www.ncbi.nlm.nih.gov/blast/) analysis showed that these primers were $97 \%$ and $90 \%$ homologous between human and mouse PPAR $\gamma 1$ mRNA and $18 \mathrm{~S}$ rRNA, respectively.

Rosiglitazone treatment. Four- and 8-month-old mice were fed rosiglitazone-containing chow for 15 days. The chow was produced by Research Diets and contained $200 \mathrm{mg} / \mathrm{kg}$ of drug; this is equivalent to a dose of 10 $\mathrm{mg} / \mathrm{kg} / \mathrm{d}$ in an adult mouse that consumes on average $4.5 \mathrm{~g} / \mathrm{d}$ of chow. These doses were similar to those used by other investigators (53).

Statistics. We analyzed data using the Prism software package (GraphPad Software). Comparisons between 2 groups were performed using unpaired 2 -tailed Student's $t$ tests. All values are presented as mean \pm SD. Differences between groups were considered statistically significant at $P<0.05$.

\section{Acknowledgments}

We thank T. Seo and Y. Hu for help with the kinetic studies and animal husbandry. This work was funded by grants HL73029, HL77113 Specialized Centers of Clinically Oriented Research (SCCOR), and HL62583 from the National Heart, Lung, and Blood Institute. M. Yokoyama and H. Yamashita were supported by a Mentor-Based Postdoctoral Fellowship from the American Diabetes Association.

Received for publication September 14, 2006, and accepted in revised form June 15, 2007.

Address correspondence to: Ira J. Goldberg, Department of Medicine, Columbia University, 630 West 168th Street, New York, New York 10032, USA. Phone: (212) 305-5961; Fax: (212) 305-5384; E-mail: ijg3@columbia.edu.
1. Lee, C.H., Olson, P., and Evans, R.M. 2003. Minireview: lipid metabolism, metabolic diseases, and peroxisome proliferator-activated receptors. Endocrinology. 144:2201-2207.

2. Staels, B., and Fruchart, J.C. 2005. Therapeutic roles of peroxisome proliferator-activated receptor agonists. Diabetes. 54:2460-2470.

3. Barger, P.M., and Kelly, D.P. 2000. PPAR signaling in the control of cardiac energy metabolism. Trends Cardiovasc. Med. 10:238-245.

4. Duan, S.Z., Ivashchenko, C.Y., Russell, M.W., Milstone, D.S., and Mortensen, R.M. 2005. Cardiomyocyte-specific knockout and agonist of peroxisome proliferator-activated receptor-gamma both induce cardiac hypertrophy in mice. Circ. Res. 97:372-379.

5. Yu, S., et al. 2003. Adipocyte-specific gene expression and adipogenic steatosis in the mouse liver due to peroxisome proliferator-activated receptor gamma1 (PPARgamma1) overexpression. J. Biol. Chem. 278:498-505.

6. Metzger, D., et al. 2005. Functional role of RXRs and PPARgamma in mature adipocytes. Prostaglandins Leukot. Essent. Fatty Acids. 73:51-58.

7. Schaffer, J.E. 2003. Lipotoxicity: when tissues overeat. Curr. Opin. Lipidol. 14:281-287.

8. Finck, B.N., et al. 2002. The cardiac phenotype induced by PPAR $\alpha$ overexpression mimics that caused by diabetes mellitus. J. Clin. Invest. 109:121-130. doi:10.1172/JCI200214080.

9. Barouch, L.A., Berkowitz, D.E., Harrison, R.W., O'Donnell, C.P., and Hare, J.M. 2003. Disruption of leptin signaling contributes to cardiac hypertrophy independently of body weight in mice. Circulation. 108:754-759.

10. Yagyu, H., et al. 2003. Lipoprotein lipase (LpL) on the surface of cardiomyocytes increases lipid uptake and produces a cardiomyopathy. J. Clin. Invest. 111:419-426. doi:10.1172/JCI200316751.

11. Chiu, H.C., et al. 2001. A novel mouse model of lipotoxic cardiomyopathy. J. Clin. Invest. 107:813-822.

12. Zhou, Y.T., et al. 2000. Lipotoxic heart disease in obese rats: implications for human obesity. Proc. Natl. Acad. Sci. U. S. A. 97:1784-1789.

13. Vikramadithyan, R.K., et al. 2005. Peroxisome proliferator-activated receptor agonists modulate heart function in transgenic mice with lipotoxic cardiomyopathy. J. Pharmacol. Exp. Ther. 313:586-593.

14. Asakawa, M., et al. 2002. Peroxisome proliferatoractivated receptor gamma plays a critical role in inhibition of cardiac hypertrophy in vitro and in vivo. Circulation. 105:1240-1246.

15. Abdelrahman, M., Sivarajah, A., and Thiemermann, C. 2005. Beneficial effects of PPAR-gamma ligands in ischemia-reperfusion injury, inflammation and shock. Cardiovasc. Res. 65:772-781.

16. Golfman, L.S., et al. 2005. Activation of PPARgamma enhances myocardial glucose oxidation and improves contractile function in isolated working hearts of ZDF rats. Am. J. Physiol. Endocrinol. Metab. 289:E328-E336.

17. Rangwala, S.M., and Lazar, M.A. 2004. Peroxisome proliferator-activated receptor gamma in diabetes and metabolism. Trends Pharmacol. Sci. 25:331-336.

18. Chawla, A., et al. 2001. A PPAR gamma-LXR-ABCA1 pathway in macrophages is involved in cholesterol efflux and atherogenesis. Mol. Cell. 7:161-171.

19. Iemitsu, M., et al. 2002. Aging-induced decrease in the PPAR-alpha level in hearts is improved by exercise training. Am. J. Physiol. Heart Circ. Physiol. 283:H1750-H1760.

20. Thai, M.V., Guruswamy, S., Cao, K.T., Pessin, J.E., and Olson, A.L. 1998. Myocyte enhancer factor 2 (MEF2)-binding site is required for GLUT4 gene expression in transgenic mice. Regulation of MEF2 DNA binding activity in insulin-deficient diabetes. J. Biol. Chem. 273:14285-14292.

21. Knight, J.B., Eyster, C.A., Griesel, B.A., and Olson, A.L. 2003. Regulation of the human GLUT4 gene promoter: interaction between a transcriptional activator and myocyte enhancer factor 2A. Proc. Natl. Acad. Sci. U. S. A. 100:14725-14730.

22. Mora, S., and Pessin, J.E. 2000. The MEF2A isoform is required for striated muscle-specific expression of the insulin-responsive GLUT4 glucose transporter. J. Biol. Chem. 275:16323-16328.

23. Michael, L.F., et al. 2001. Restoration of insulin-sensitive glucose transporter (GLUT4) gene expression in muscle cells by the transcriptional coactivator PGC-1. Proc. Natl. Acad. Sci. U. S. A. 98:3820-3825.

24. Wang, M.Y., and Unger, R.H. 2005. Role of PP2C in cardiac lipid accumulation in obese rodents and its prevention by troglitazone. Am. J. Physiol. Endocrinol. Metab. 288:E216-E221.

25. Unger, R.H. 2002. Lipotoxic diseases. Annu. Rev. Med. 53:319-336.

26. Jones, J.R., et al. 2005. Deletion of PPARgamma in adipose tissues of mice protects against high fat diet-induced obesity and insulin resistance. Proc. Natl. Acad. Sci. U. S. A. 102:6207-6212.

27. Zhang, J., et al. 2004. Selective disruption of PPARgamma 2 impairs the development of adipose tissue and insulin sensitivity. Proc. Natl. Acad. Sci. U. S. A. 101:10703-10708.

28. Gavrilova, O., et al. 2003. Liver peroxisome proliferator-activated receptor gamma contributes to hepatic steatosis, triglyceride clearance, and regulation of body fat mass. J. Biol. Chem. 278:34268-34276.

29. Wang, Y.X., et al. 2003. Peroxisome-proliferatoractivated receptor delta activates fat metabolism to prevent obesity. Cell. 113:159-170.

30. Braissant, O., Foufelle, F., Scotto, C., Dauca, M., and Wahli, W. 1996. Differential expression of peroxisome proliferator-activated receptors (PPARs): tissue distribution of PPAR-alpha, -beta, and -gamma in the adult rat. Endocrinology. 137:354-366.

31. Soto, P.F., et al. 2003. Impact of aging on myocardi- al metabolic response to dobutamine. Am. J. Physiol. Heart Circ. Physiol. 285:H2158-H2164.

32. Taegtmeyer, H., McNulty, P., and Young, M.E. 2002. Adaptation and maladaptation of the heart in diabetes: Part I: general concepts. Circulation. 105:1727-1733.

33. Listenberger, L.L., and Schaffer, J.E. 2002. Mechanisms of lipoapoptosis: implications for human heart disease. Trends Cardiovasc. Med. 12:134-138.

34. Yokoyama, M., et al. 2004. Apolipoprotein B production reduces lipotoxic cardiomyopathy: studies in heart-specific lipoprotein lipase transgenic mouse. J. Biol. Chem. 279:4204-4211.

35. Garvey, W.T., Hardin, D., Juhaszova, M., and Dominguez, J.H. 1993. Effects of diabetes on myocardial glucose transport system in rats: implications for diabetic cardiomyopathy. Am. J. Physiol. 264:H837-H844.

36. Depre, C., et al. 2000. Streptozotocin-induced changes in cardiac gene expression in the absence of severe contractile dysfunction. J. Mol. Cell. Cardiol. 32:985-996.

37. Mora, S., Yang, C., Ryder, J.W., Boeglin, D., and Pessin, J.E. 2001. The MEF2A and MEF2D isoforms are differentially regulated in muscle and adipose tissue during states of insulin deficiency. Endocrinology. 142:1999-2004.

38. Al-Khalili, L., et al. 2005. Enhanced insulin-stimulated glycogen synthesis in response to insulin, metformin or rosiglitazone is associated with increased mRNA expression of GLUT4 and peroxisomal proliferator activator receptor gamma co-activator 1. Diabetologia. 48:1173-1179.

39. Holland, W.L., et al. 2007. Inhibition of ceramide synthesis ameliorates glucocorticoid-, saturatedfat-, and obesity-induced insulin resistance. Cell Metab. 5:167-179.

40. Shimabukuro, M., Zhou, Y.T., Levi, M., and Unger, R.H. 1998. Fatty acid-induced beta cell apoptosis: a link between obesity and diabetes. Proc. Natl. Acad. Sci. U. S. A. 95:2498-2502.

41. Wu, J., and Kaufman, R.J. 2006. From acute ER stress to physiological roles of the unfolded protein response. Cell Death Differ. 13:374-384.

42. Oyadomari, S., and Mori, M. 2004. Roles of CHOP/ GADD153 in endoplasmic reticulum stress. Cell Death Differ. 11:381-389.

43. Nesto, R.W., et al. 2003. Thiazolidinedione use, fluid retention, and congestive heart failure: a consensus statement from the American Heart Association and American Diabetes Association. Circulation. 108:2941-2948.

44. Dormandy, J.A., et al. 2005. Secondary prevention of macrovascular events in patients with type 2 diabetes in the PROactive Study (PROspective pioglitAzone Clinical Trial In macroVascular Events): a randomised controlled trial. Lancet. 366:1279-1289. 
45. Gerstein, H.C., et al. 2006. Effect of rosiglitazone on the frequency of diabetes in patients with impaired glucose tolerance or impaired fasting glucose: a randomised controlled trial. Lancet. 368:1096-1105.

46. Nissen, S.E., Wolski, K., and Topol, E.J. 2005. Effect of muraglitazar on death and major adverse cardiovascular events in patients with type 2 diabetes mellitus. JAMA. 294:2581-2586.

47. Zhang, H., et al. 2005. Collecting duct-specific deletion of peroxisome proliferator-activated receptor gamma blocks thiazolidinedione- induced fluid retention. Proc. Natl. Acad. Sci. U. S. A. 102:9406-9411.

48. Guan, Y., et al. 2005. Thiazolidinediones expand body fluid volume through PPARgamma stimulation of ENaC-mediated renal salt absorption. Nat. Med. 11:861-866.

49. Staels, B. 2005. Fluid retention mediated by renal PPARgamma. Cell Metab. 2:77-78.

50. Folch, J., Lees, M., and Sloane Stanley, G.H. 1957. A simple method for the isolation and purification of total lipides from animal tissues. J. Biol. Chem. 226:497-509.
51. Seo, T., et al. 2000. Lipoprotein lipase-mediated selective uptake from low density lipoprotein requires cell surface proteoglycans and is independent of scavenger receptor class B type 1. J. Biol. Chem. 275:30355-30362.

52. Perry, D.K., Bielawska, A., and Hannun, Y.A. 2000. Quantitative determination of ceramide using diglyceride kinase. Methods Enzymol. 312:22-31.

53. Watkins, S.M., Reifsnyder, P.R., Pan, H.J., German, J.B., and Leiter, E.H. 2002. Lipid metabolome-wide effects of the PPARgamma agonist rosiglitazone. J. Lipid Res. 43:1809-1817. 